\title{
专题：地球生物学前沿
}

论 文

\section{广西杨堤剖面上泥盆统弗拉阶-法门阶之交磷质 微球粒的发现及其地球生物学意义}

\author{
黄程，龚一鸣* \\ 中国地质大学生物地质与环境地质国家重点实验室, 武汉 430074 \\ * 联系人, E-mail: ymgong@cug.edu.cn
}

收稿日期: 2013-07-06; 接受日期: 2014-02-24; 网络版发表日期: 2014-05-12

国家重点基础研究计划项目(编号: 2011CB808800)、国家自然科学基金项目(批准号: 41290260, 41072252)和高等学校博士学科点专项科研 基金项目(编号: 20120145110012)资助

\begin{abstract}
摘要利用醋酸酸解法处理广西桂林杨堤剖面上泥盆统弗拉阶-法门阶(F-F)之交的样品, 获 得了大量保存完好的磷质微球粒。其直径为 $150 \mu \mathrm{m}$ 左右，球状、扁球状或椭球状，球体外表 面光滑，并发育脐状浅凹，球体为实心，内部由浅色的磷灰石和深色的有机质相间分布形成 同心环带结构. 所有磷质微球粒与牙形刺共同保存，而磷质微球粒的丰度明显低于同层位的牙 形刺. 显微激光拉曼微区分析表明: 磷质微球粒的外壳和内核的拉曼光谱特征分别与牙形刺 Palmatolepis sp.的齿片和齿台十分类似. 此外，磷质微球粒的富集与藻类生物繁盛在时间上基 本一致，而滞后于海水营养盐激增. 基于磷质微球粒与牙形刺在丰度的相关性、成分的相似性 以及与鱼类耳石在形态和结构特征方面的相似性，本文认为磷质微球粒可能是牙形动物的“耳 石”，其形成可能与海水富营养化有关. 晚泥盆世陆源输入的增加、海底热液活动以及缺氧的底 层海水上涌等活动可能导致了海水营养盐富集, 并由此诱发菌藻类生物的繁盛, 从而可能刺激 了牙形动物分泌磷质微球粒——牙形动物 “耳石”. 本文以磷质微球粒为纽带揭示了生物-环境 之间的耦合关系，为晚泥盆世 F-F 之交的生物灭绝成因提供了新的证据.
\end{abstract}

关键词

微球粒

牙形动物

耳石

富营养化

泥盆纪

F-F

华南
晚泥盆世弗拉阶-法门阶(F-F) 事件(或称 Kellwasser 事件) 是显生宙 5 次重大生物灭绝事件之一 (Raup 和 Sepkoski, 1982; Buggisch, 1991; McGhee, 1996). 这次事件具有灾难性、全球性、同时性、选择 性和多幕性的特点(廖卫华, 2001; 龚一鸣等, 2002c). 低纬度热带-亚热带礁生态系统、浅水生态系统明显 遭到严重破坏, 而高纬度生态系统、深水生态系统以 及陆地生态系统所受影响甚微 (Buggisch, 1991; Joachimski 和 Buggisch, 1993; McGhee, 1996). 对于造
成此次生物灭绝原因的解释仍争论不休, 但是从广义 上可分为两大类(廖卫华, 2004)：地外(McLaren, 1970; Sandberg 等, 2002; 杜远生等, 2008)和地内(Copper, 1986; Walliser, 1996; Chen 等, 2005; 徐申等, 2006).

科学家们试图从生物地层(Wang 和 Ziegler, 2002; 廖卫华, 2004; 王玉净和罗辉, 2004; Stigall, 2012)、层 序地层 (Johnson 等, 1985; 龚一鸣等, 1997; Ver Straeten 等, 2011)、事件地层(Wang 等, 1993; Claeys 和 Casier, 1994; Racki, 1998, 2012)、化学地层(Bai 等,

中文引用格式: 黄程, 龚一鸣. 2014. 广西杨堤剖面上泥盆统弗拉阶-法门阶之交磷质微球粒的发现及其地球生物学意义. 中国科学: 地球科学, 44: 1171-1184 英文引用格式: Huang C, Gong Y M. 2014. Phosphatic microspherules and their geobiological implications from the Frasnian-Famennian transition at the Yangdi section, Guilin, South China. Science China: Earth Sciences, 57: 943-956, doi: 10.1007/s11430-014-4847-y 
1994; Murphy 等, 2000; Ma 和 Bai, 2002)、同位素地层 (Joachimski 和 Buggisch, 1993; Xu 等, 2008, 2012; Joachimski 等, 2009)和分子地层(Joachimski 等, 2001; 龚一鸣等, 2002a, 2005)等角度, 寻找 F-F 之交环境突 变的证据. 大量的资料表明, 在重大地质突变期往往 保存有大量的微球粒(Simonson 和 Glass, 2004; Glass 和 Simonson, 2012), 这些微球粒通常是跨越微观和 宇观研究的重要信息载体(黄程等, 2012). 到目前为 止，晚泥盆世大量的微球粒已在北美、澳大利亚、比 利时以及华南等地相继报道(Glenister 等, 1976; Claeys 等, 1992; Wang, 1992; Wang 和 Chatterton, 1993; Bai 等, 1994; Claeys 和 Casier, 1994; 龚一鸣等, 2001; Giles 等, 2002; Ma 和 Bai, 2002). 尽管 F-F 之交发现了可能 的撞击成因的微球粒, 但是在时间上却与生物灭绝事 件不一致(Claeys 等, 1992; Wang, 1992; Claeys 和 Casier, 1994; Ma 和 Bai, 2002; Glass 和 Simonson, 2012), 因此, 生物灭绝与地外撞击没有确丵的因果关 系. 由于磷质微球粒分布广泛, 因而过去的研究中很 少将其与灭绝事件相联系. 前人对磷质的微球粒研究 仅限于微球粒本身(Stauffer, 1935; Leuteritz 等, 1972; Glenister 等, 1976; 龚一鸣等, 2001), 很少结合环境和 生物进行综合分析(Giles 等, 2002), 以致很难合理解 释磷质微球粒的具体成因机制, 也忽视了磷质微球粒 的地球生物学意义. 在对广西桂林杨堤剖面 F-F 之交 的磷质微球粒的精细解剖的基础之上，结合牙形刺、 地微生物以及全岩地球化学数据, 我们探讨了磷质微 球粒可能的成因机制及其地球生物学意义, 为 F-F 之 交生物灭绝的成因解释提供了新的线索.

\section{1 地质背景与研究方法}

属于华南地区的广西, 在晚古生代处于拉张构 造环境(曾允孚等, 1993; 吴诒等, 1997), 从早泥盆世 晚埃姆斯期到法门期, 形成了一系列的北东、北西向 的同沉积断裂, 造就了独特的台地-台间裂陷海槽交 替、棋盘式的古地理格局(图 1)(杜远生等, 2008).

杨堤剖面(也称为付合剖面)位于广西桂林市东 南的杨堤镇付合水库旁. 该剖面 F-F 之交以灰色-深 灰色灰岩夹泥岩, 灰色瘤状灰岩沉积为主, 属碳酸盐 台地斜坡相(图 1). 前人已在该剖面建立了牙形刺生 物地层(季强, 1994), 并利用米兰科维奇旋回对牙形 刺生物带进行了数字定年(Gong 等, 2001; 龚一鸣等,
2004), 建立了精确的时间坐标. 此外, 前人还在该剖 面开展了化学地层、层序地层以及分子地层等工作 (龚一鸣等, 2002c, 2005; Chen 和 Tucker, 2003; Chen 等, 2005). 这些工作为阐明 F-F 之交生物-环境事件 提供了重要理论基础.

研究样品采自杨堤剖面弗拉阶下 Palmatolepis rhenana 带顶部至法门阶上 Palmatolepis triangularis 带灰岩. 将灰岩样品溶解于浓度为 $10 \%$ 的醋酸中. 利 用双目显微镜从粒径 60 830 $\mu \mathrm{m}$ 的篎洗残渣中挑选 微球粒和微体化石, 并逐层统计微球粒的数量(图 2). 将代表性的微球粒按不同方位进行扫描电镜照相, 并对微球粒的切面进行激光拉曼微区分析. 激光拉 曼测试的仪器为激光共焦显微拉曼光谱仪 (DXR Raman Microscope), 以固体激光器作激发光源, 激 光线波长 $532 \mathrm{~nm}$, 照射在样品表面的功率 $5.0 \mathrm{~mW}$, 狭缝 $50 \mu \mathrm{m}$, 曝光时间 $10 \mathrm{~s}$, 物镜放大倍数 50 倍; 拉 曼强度由 5 次连续扫描获得, 仪器分辨率 $0.6 \mu \mathrm{m}$, 扫 描范围 200 3500 $\mathrm{cm}^{-1}$. 上述测试均在中国地质大学 地质矿产过程与资源国家重点实验室完成.

\section{2 微球粒与牙形刺的分布}

通过对整个剖面的研究发现, 微球粒主要分布 于整个上 Pa. rhenana 带和 Palmatolepis linguiformis 带的顶部(图 2). 产出的层位中以上Pa. rhenana 带顶 部和 Pa. linguiformis 带顶部的微球粒含量最丰富, 其 丰度分别为 76 和 31 个 $/ \mathrm{kg}$. 在这些富含微球粒的层位 中, 通常以大量的菌藻类微生物发育为特征(图 2). 在不溶的残渣中, 除了赋存微球粒外, 同时还有其他 微体化石: 牙形刺、介形虫、竹节石和疑源类等. 此 外, 部分岩石薄片中可见腕足和海百合生物碎屑. 这 些化石中, 牙形刺与微球粒关系最为密切, 微球粒均 来自含牙形刺的样品中, 但是含牙形刺的样品中却 不是都有微球粒. 根据两者丰度统计结果发现, 除上 Pa. rhenana 带顶部(26 层)外，其他层位中牙形刺的 丰度均高于微球粒(图 2).

\section{3 微球粒物理和化学特征}

微球粒呈球状、椭球状或扁球状，直径 120 200 $\mu \mathrm{m}$, 平均为 $\pm 150 \mu \mathrm{m}$. 在双目显微镜下观察微球粒的 颜色为蜜黄色至黑色, 玻璃光泽, 性脆. 所有微球 


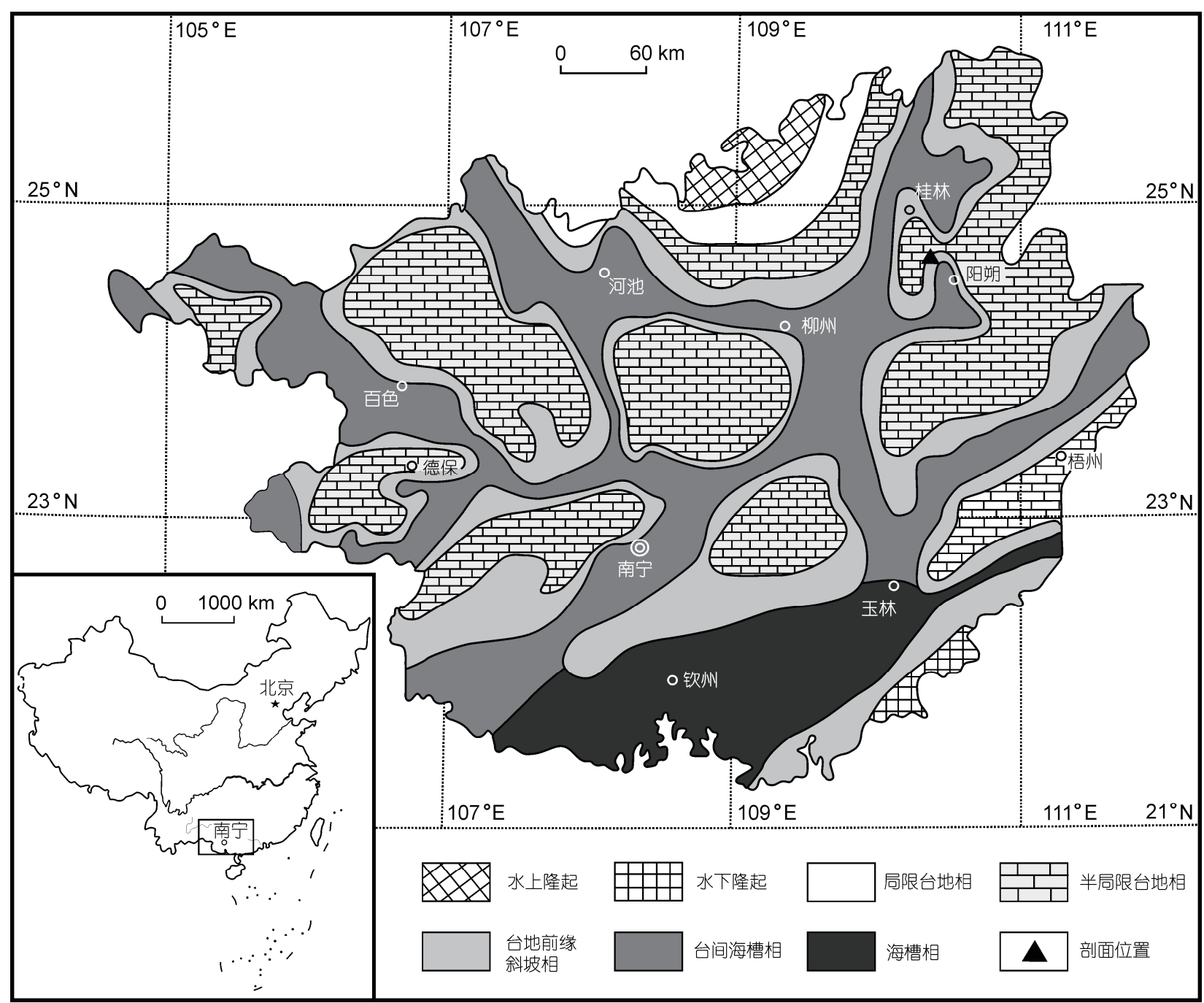

图 1 广西晚泥盆世 F-F 之交岩相古地理图和研究剖面位置

据吴诒等(1987)和龚一鸣等(2002b)绘制

粒均只有一个脐状浅凹(dimple), 由于脐状浅凹的外 缘存在一宽缓的浅沟, 使脐状浅凹的外缘呈现微凸 状(图 3). 本文中微球粒的这种脐状浅凹结构比前人 的更加典型(Glenister 等, 1976; Wang 和 Chatterton, 1993; 龚一鸣等, 2001; Giles 等, 2002), 并且每个微 球粒的凹坑深浅程度也不一致. 球体的表面在双目 显微镜下显示较光滑, 通过扫描电镜放大后, 部分微 球粒可见溶蚀的空洞(图 3(a), (c), (d), (g)和(i)), 空洞 多为不规则状, 少量为规则的四边形, 部分球体溶蚀 空洞可见纤维束状晶体, 晶体垂直于球面生长 (图 3(c)). 根据能谱 (EDX) 和激光拉曼光谱分析结果 显示, 微球粒的主要矿物成分为磷灰石(谱图见下文).
球体为实心, 从球体径向看, 清晰可见放射纤维状的 磷灰石晶体围绕中心呈同心层状分布(图 4(b)和(c)). 这些特征表明, 球体内部的三维结构是由放射状磷 灰石晶体组成不同直径的同心球层堆砌而成. 从平 行和垂直脐状凹坑结构的球体切面看，由明、暗相间 的环带围绕内核呈同心状分布(图 4(d)), 脐状浅凹部 位的同心环带在一定厚度范围内重复向内凹生长. 环带的宽度一致, 浅色带宽度约为 $1 \sim 1.5 \mu \mathrm{m}$, 暗色带 宽度约为 $0.5 \sim 0.8 \mu \mathrm{m}$. 球体不同部位的透光性不一致, 内核颜色较深, 外壳颜色较浅(图 4(d)). 部分球体靠 外壳部位含有弥散状分布的不透明的石墨矿物颗粒 (证据见下文), 并且部分石墨颗粒切割了微球粒的环 


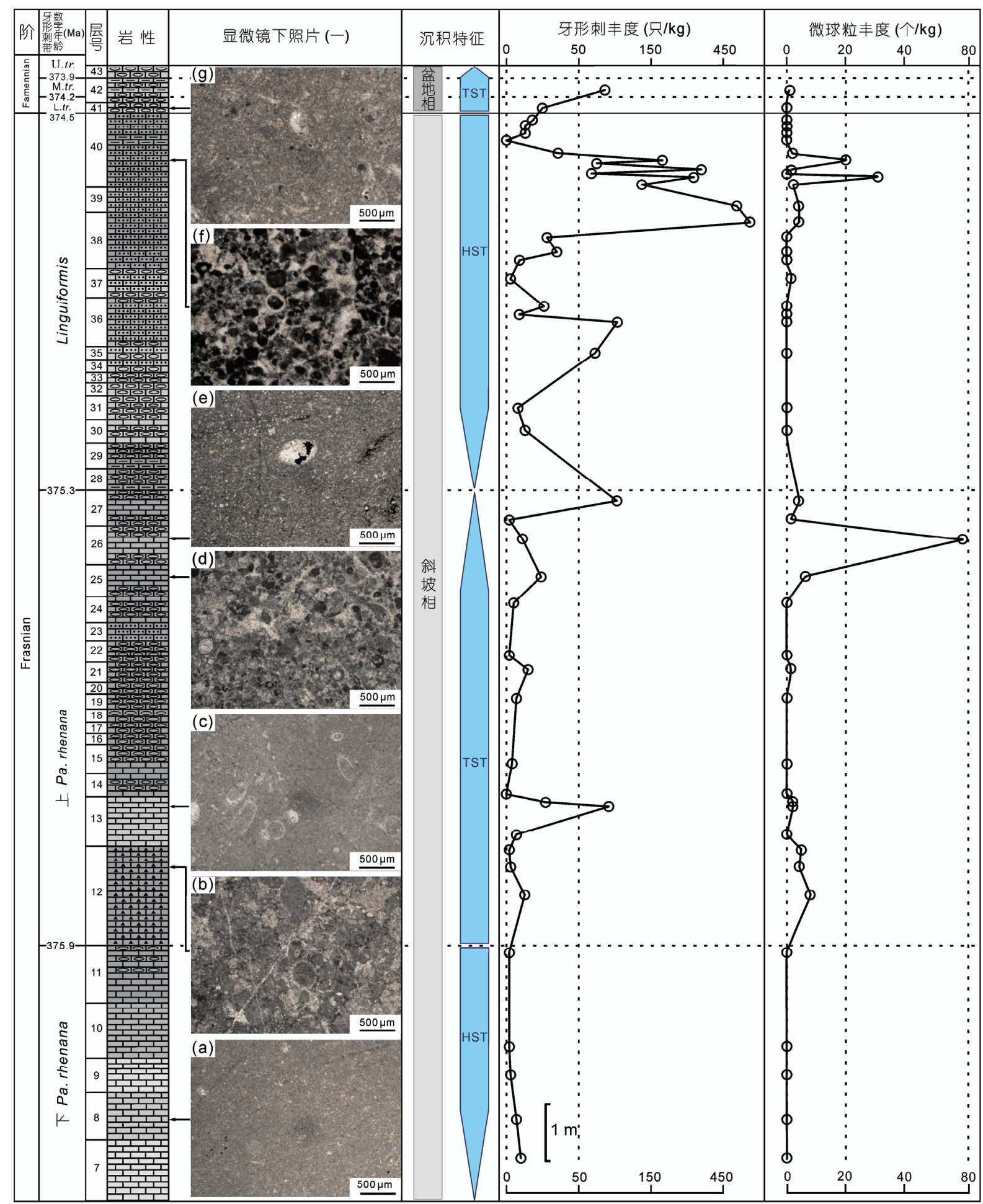

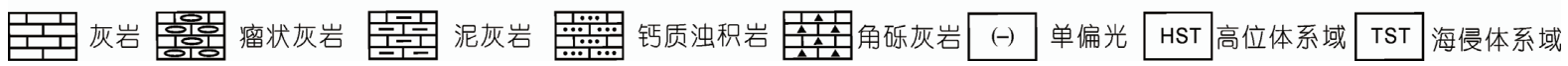

图 2 广西杨堤剖面晚泥盆世 F-F 之交生物地层和沉积地层以及牙形刺和微球粒丰度统计

(a), (c), (e) 和 (g) 示粒泥灰岩, 含腕足、竹节石和介形虫; (b), (d)和(f)示泥粒灰岩, 含丰富的菌藻类微生物. 牙形刺生物地层引自季强(1994), 牙形刺带数字年龄引自 Gong 等(2001)和龚一鸣等(2004), 沉积地层数据引自龚一鸣等(2005) 

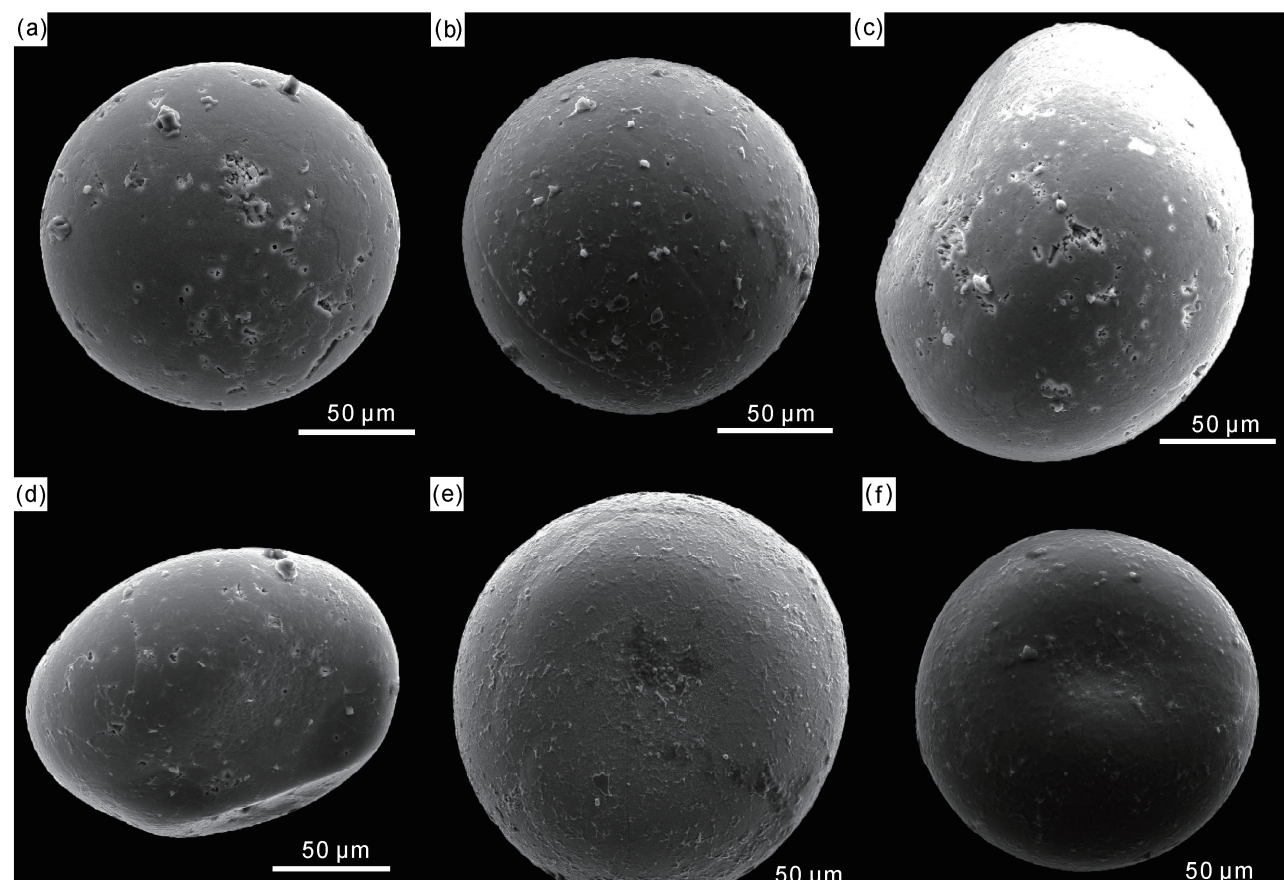

(e)

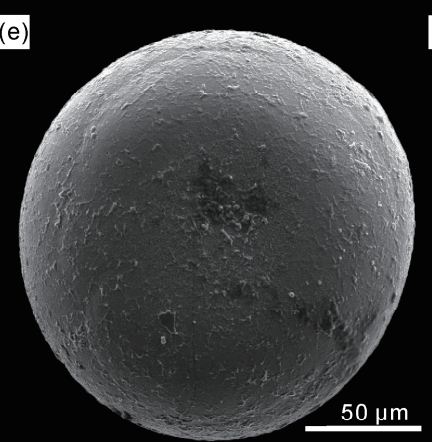

(f)

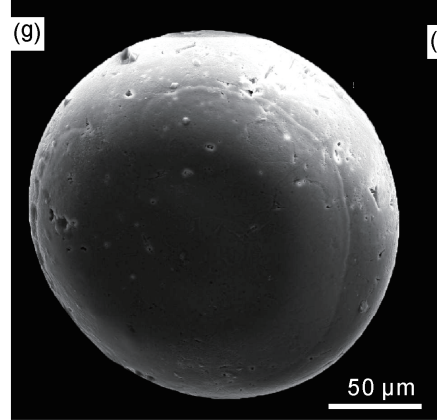

(h)
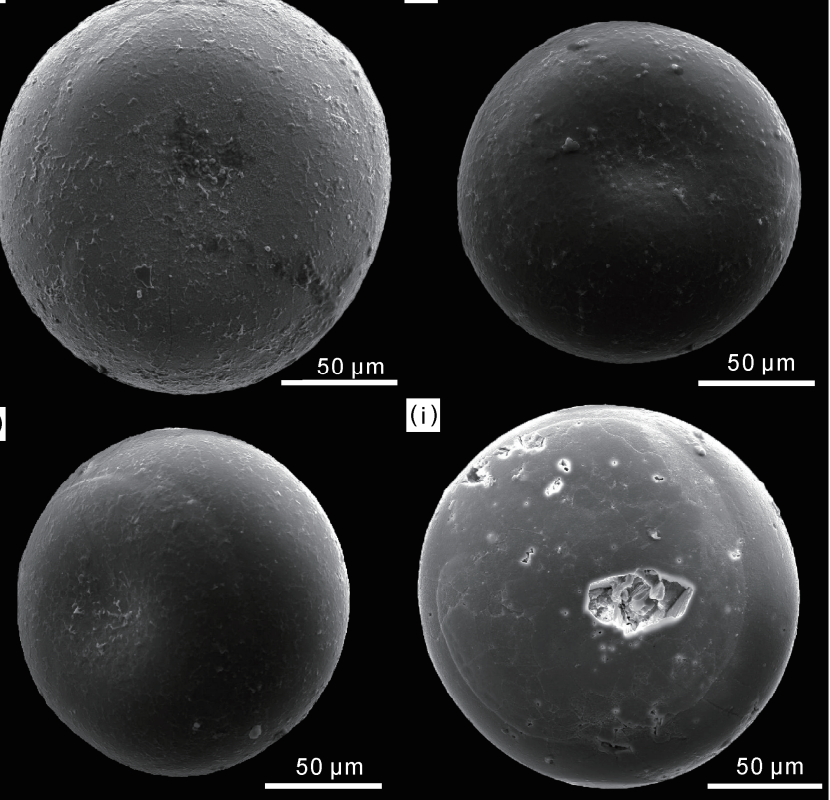

图 3 磷质微球粒在不同方位的形貌特征

(a), (b), (d), (g)和(i)示微球粒表面发育溶蚀孔; (c)示微球粒表面矿物被溶蚀后显示垂直表面的针状晶体; (c) (i)示不同方位微球粒表面的脐状 结构; (e) (i)示脐状结构外边缘发育宽缓的浅沟

带(图 4(d)). 综合以上特征可以看出, 杨堤剖面的磷 质微球粒与前人研究的磷质微球粒既有相似之处 (Glenister等, 1976; Wang 和 Chatterton, 1993; Giles 等, 2002), 也存在不同点: 所有微球粒均只发育一个脐 状浅凹结构, 浅凹外缘微凸; 微球粒外部的同心环带 结构较内核更清晰; 部分微球粒靠外壳部位含有弥 散状分布的石墨矿物颗粒.

通过对两类具有代表性的磷质微球粒球外壳和 内核激光拉曼微区分析表明, 在 $200 \sim 2000 \mathrm{~cm}^{-1}$ 波数 范围内, 可识别出 2 个共同的拉曼特征谱峰段, 分别 位于 1611 1326 和 431 1059 $\mathrm{cm}^{-1}$, 分别代表碳峰段、 磷灰石峰段(Pasteris 和 Wopenka, 2003; Marshall 等,
2010), 即分别与深色的碳质和浅色的磷灰石有关(图 5). 碳峰段：包括“石墨峰”(G 峰) $\left(\sim 1607 \mathrm{~cm}^{-1}\right)$ 和缺陷 峰(D 峰) $\left(\sim 1335 \mathrm{~cm}^{-1}\right)$, 在球外壳和内核中均有显示, 前者与芳香构型层面上双碳原子键的 $\mathrm{E}_{2 \mathrm{~g} 2}$ 伸展振动 有关(Pasteris 和 Wopenka, 2003; Marshall 等, 2010; Bower 等, 2013), 后者与碳质的无序结构和结构单元 间的缺陷有关(Pasteris 和 Wopenka, 2003; Marshall 等, 2010; Bower 等, 2013). 从外壳至内核：两种微球粒 的碳峰(G 峰和 D 峰)半高宽均增加, 碳质非均匀分布 的微球粒(样品 $\mathrm{Y} 25$ )内核的 $\mathrm{D}$ 峰和 $\mathrm{G}$ 峰强度分别为外 壳的 7 倍、10 倍左右, $\mathrm{D}$ 峰和 $\mathrm{G}$ 峰强度比 $\left(I_{\mathrm{D}} / I_{\mathrm{G}}\right)$, 从 1.03 减少至 0.73 ; 而碳质均匀分布的微球粒(样品 


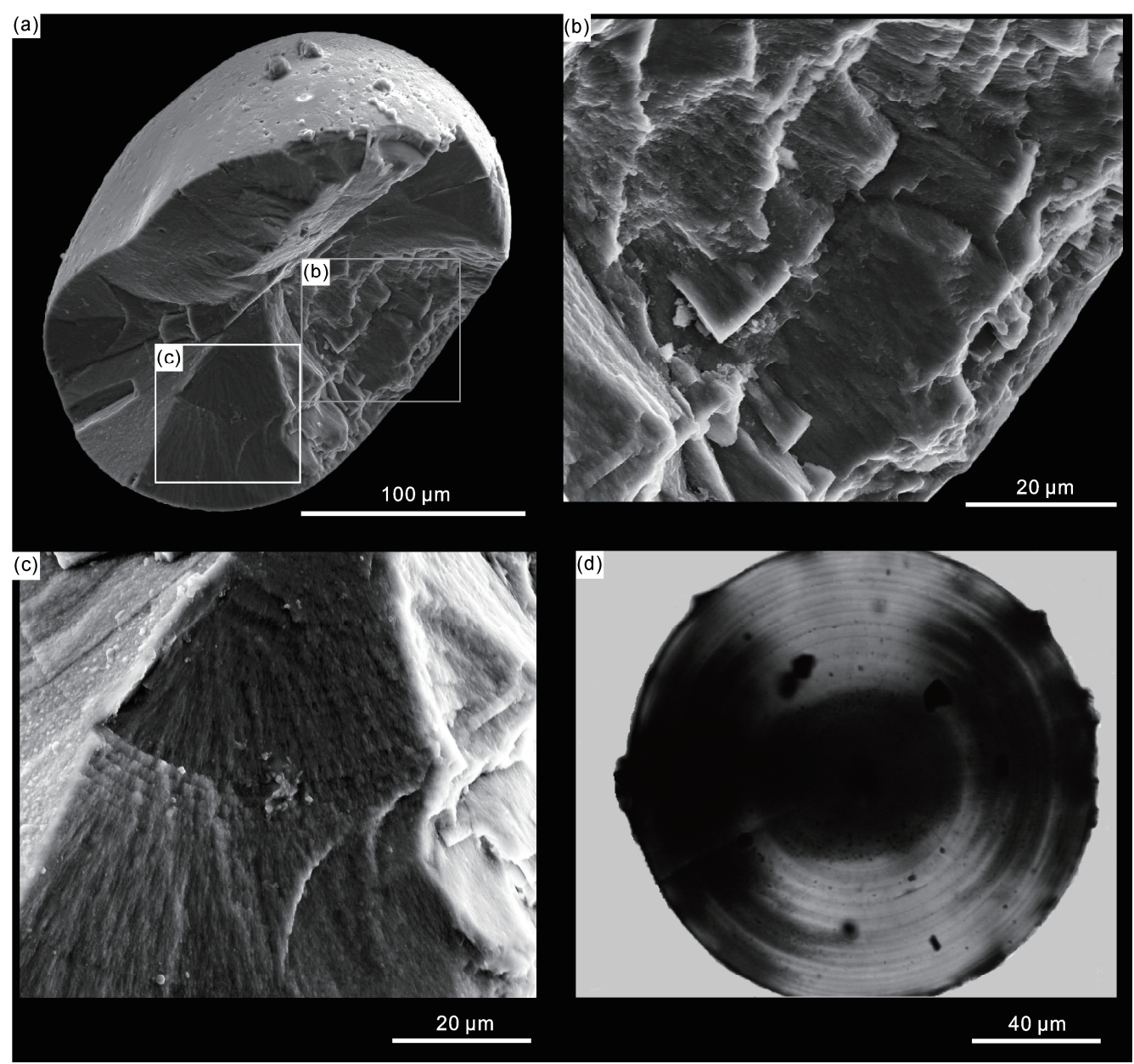

图 4 磷质微球粒表面和内部结构与形貌

(a)为微球粒断裂面的扫描电镜图; (b)和(c)为 (a)中矩形框放大, 显示放射状的磷灰石晶体呈同心层状分布; (d)为球体切面在 DXR 光学显微镜 下照片，显示同心层状的浅色磷灰石晶体和深色有机质围绕内核相间分布

Y 40C)的碳峰半高宽增加幅度较小, 峰的强度略微减 小, $\mathrm{D}$ 峰和 $\mathrm{G}$ 峰强度比 $\left(I_{\mathrm{D}} / I_{\mathrm{G}}\right)$ 从 1.19 减少至 1.06 (表 1$)$. 磷灰石峰段: 主峰拉曼位移为 $964 \mathrm{~cm}^{-1}$, 在整个球体 中均有显示. 从外壳至内核: 两种微球粒的磷灰石峰 半高宽变化不大; 外壳和内核的磷灰石峰强度比, 在 碳质均匀分布的微球粒中为 1.96 , 在碳质非均匀分 布的微球粒中为 1.06. 除了外壳的碳峰外, 碳质非均 分布的微球粒拉曼峰强度在外壳和内核部位，均高 于碳质非均分布的微球粒. 碳质非均匀分布的微球 粒外壳中明显有碳的倍频峰, 反映了碳质三维结构 的有序度(Pasteris 和 Wopenka, 2003). 因此, 同一微 球粒的不同部位、不同微球粒的相同部位的物质组 成、赋存状态以及结构特征既有相似之处, 也存在明
显的不同。

通过对牙形刺属 Palmatolepis sp.的齿片和齿台 进行激光拉曼光谱微区分析后, 发现这些部位仍然 发育碳峰、磷灰石峰(图 5(e)和(f)). 更为重要的是, 牙 形刺属 Palmatolepis sp.的齿片和齿台的拉曼谱特征 分别与碳质非均匀分布的磷质微球粒的外壳和内核 部位十分类似(图 5). 但是牙形刺齿片的碳峰强度是 磷质微球粒外壳的 5 7 倍左右, 磷灰石峰强度是其 2 倍左右; 牙形刺齿台的碳峰强度是磷质微球粒内核 的 3 倍左右, 两者磷灰石峰的强度相差不大(表 1$)$. 这 些特征表明牙形刺属 Palmatolepis sp.的齿片和齿台 的物质组成和结构分别与磷质微球粒外壳和内核存 在相似之处, 但是两者的结晶程度和有序度存在差 

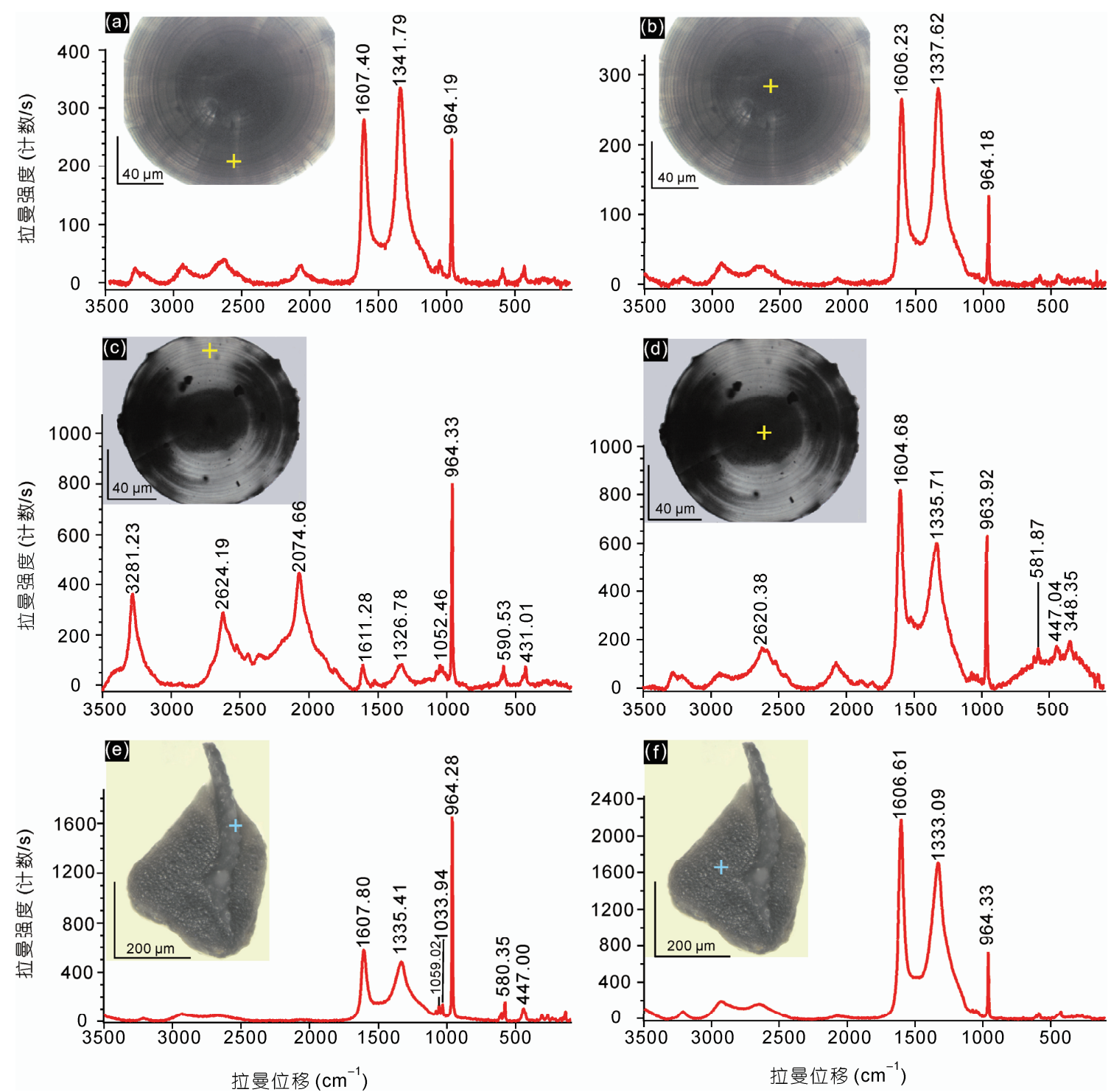

图 5 磷质微球粒和牙形刺属 Palmatolepis sp.的激光拉曼谱图

(a)和(b)分别为碳均匀分布的磷质微球粒外壳和内核的拉曼谱图(样品号 Y40C); (c)和(d)分别为碳质非均匀分布的磷质微球粒外壳和内核的 拉曼谱图(样品号 Y25); (e)和(f)分别为牙形刺属 Palmatolepis sp.齿片和齿台的拉曼谱图

异，前者明显较高.

\section{4 讨论}

磷质微球粒的内核相对于外壳的激光拉曼光谱 的变化(表 1): $R_{I}\left(I_{\mathrm{D}} / I_{\mathrm{G}}\right)$ 值明显减小，磷灰石峰的强度 稍有减弱，反映磷质微球粒中内核相对于外壳的碳 质有序度和晶体大小增加, 而磷灰石晶体却是相反 的较弱变化趋势(Escribano 等, 2001; Pasteris 和
Wopenka, 2003; Marshall 等, 2010; Bower 等, 2013). 此外, $R_{1}$ 值的高低还可以反映碳物质的热成熟度, $R_{1}$ 值越大，热蚀变程度越高(Bower 等, 2013)。因此，碳 质均匀分布的微球粒受后期热蚀变程度高于碳质非 均匀分布的微球粒和牙形刺属 Palmatolepis sp., 而且 碳质非均匀分布的微球粒的外壳受热蚀变程度明显 高于内核. 此外, 外壳的 $\Gamma_{\mathrm{D}}$ 值(D 峰半高宽)相对于内 核增加, 反映了磷质微球粒外壳的石墨碳较多, 而内 核的无定型碳较多(Bower 等, 2013). 特别是在碳质 
表 1 磷质微球粒和牙形刺的拉曼光谱参数 ${ }^{\text {a) }}$

\begin{tabular}{|c|c|c|c|c|c|c|c|c|c|c|}
\hline 样品 & $\begin{array}{c}\mathrm{P} \text { 峰位置 } \\
\left(\mathrm{cm}^{-1}\right)\end{array}$ & $\begin{array}{l}\mathrm{P} \text { 峰强度 } \\
\text { (counts/s) }\end{array}$ & $\Gamma_{\mathrm{P}}$ & $\begin{array}{c}\mathrm{D} \text { 峰位置 } \\
\left(\mathrm{cm}^{-1}\right)\end{array}$ & $\begin{array}{l}\mathrm{D} \text { 峰强度 } \\
\text { (counts/s) }\end{array}$ & $\Gamma_{\mathrm{D}}$ & $\begin{array}{c}\mathrm{G} \text { 峰位置 } \\
\left(\mathrm{cm}^{-1}\right)\end{array}$ & $\begin{array}{c}\mathrm{G} \text { 峰强度 } \\
\text { (counts/s) }\end{array}$ & $\Gamma_{\mathrm{G}}$ & $R_{1}$ \\
\hline 微球粒 Y40C 外壳 & 964.19 & 247.29 & 10 & 1341.79 & 334.87 & 82 & 1607.40 & 280.52 & 52 & 1.19 \\
\hline 微球粒 Y40C 内核 & 964.18 & 126.36 & 10 & 1337.62 & 280.42 & 90 & 1606.23 & 264.10 & 53 & 1.06 \\
\hline 微球粒 Y25 外壳 & 964.33 & 671.69 & 10 & 1326.78 & 82.69 & 78 & 1611.28 & 79.98 & 29 & 1.03 \\
\hline 微球粒 Y25 内核 & 963.92 & 630.19 & 9 & 1335.71 & 601.56 & 151 & 1604.68 & 816.96 & 55 & 0.73 \\
\hline Palmatolepis sp.齿片 & 964.28 & 1652.84 & 6 & 1335.41 & 479.31 & 131 & 1607.80 & 573.87 & 26 & 0.83 \\
\hline Palmatolepis sp.齿台 & 964.33 & 721.19 & 6 & 1333.09 & 1694.65 & 122 & 1606.61 & 2169.04 & 44 & 0.78 \\
\hline
\end{tabular}

a) P 峰代表磷灰石峰; $\Gamma_{\mathrm{P}}, \Gamma_{\mathrm{D}}$ 和 $\Gamma_{\mathrm{G}}$ 分别代表磷灰石、 $\mathrm{D}$ 峰、 $\mathrm{G}$ 峰的半高宽; $R_{\mathrm{l}}=I_{\mathrm{D}} / I_{\mathrm{G}}(\mathrm{D}$ 峰强度 $/ \mathrm{G}$ 峰强度 $)$

非均匀分布的磷质微球粒中的石墨矿物颗粒(图 4(d)), 可能就是碳质三维有序度增加而出现碳的倍频峰的 原因(Pasteris 和 Wopenka, 2003). 这些石墨矿物颗粒 可能是后期非均一性热蚀变的产物, 并有石墨矿物 颗粒切割早期环带结构的证据支持.

\section{1 磷质微球粒可能是牙形动物“耳石”}

初始的沉积有机质成分随着热蚀变程度的增加, $\mathrm{H}, \mathrm{O}$ 和 $\mathrm{N}$ 以及硫化物被释放, 最终以石墨化结构的 形式保存下来，这就使大量的生物学信息丢失 (Marshall 等, 2010; Bower 等, 2013). 长期以来, 科学 家们利用碳峰 (D 峰和 $\mathrm{G}$ 峰)参数作为判断化石中生物 来源的碳的重要判据(Schopf 等, 2002; Bower 等, 2013)，但是其他非生物来源的碳也有同样的拉曼谱 特征(Marshall 等, 2010; Bower 等, 2013), 两者很难区 分. 因此, 激光拉曼的碳峰是判定生命证据的必要非 充分条件(Pasteris 和 Wopenka, 2003), 还必须对不同 来源的碳峰的参数进行区分和对比. 为有效判定碳 质来源, Bower 等(2013)利用 $\Gamma_{\mathrm{D}}$ (D 峰的半高宽)与 $R_{1}$ $\left(I_{\mathrm{D}} / I_{\mathrm{G}}\right)$ 的关系(图 6), 划分出了不同碳质来源的图解区 域. 本文研究利用 Bower 等(2013)提出的方法, 对磷 质微球粒和牙形刺属 Palmatolepis sp. 拉曼光谱的 $\Gamma_{\mathrm{D}}$ 与 $R_{1}$ 值进行投图 (图 6), 结果显示磷质微球粒和牙形 刺属 Palmatolepis sp. 中初始的碳都为复杂的有机物, 证明了磷质微球粒的形成与生物密切相关.

自从 Stauffer(1935, 1940)首次发现奥陶纪和泥盆 纪地层中与牙形刺密切共生的磷质微球粒以来, 通 过其形貌、内部结构以及成分特征精细解剖后, 多数 学者认为磷质微球粒形成与生物密切相关, 对此提 出了多种解释和推断：牙形动物 “卵壳”(Stauffer, 1935，1940); 牙形动物“耳石”(Youngquist 和 Miller,
1948); 牙形刺“珍珠”(Glenister 等，1976; Wang 和 Chatterton, 1993); 牙形动物卵细胞(龚一鸣等, 2001); 鱼耳石(Giles 等, 2002); 刺胞动物耳石(Bischoff, 1973) 等. 甚至有学者认为它们是无机沉积物(Leuteritz 等, 1972), 但是后来很快就被否定了(Glenister 等, 1976). 由于缺乏足够证据支撑, 这些解释通常都只能解释 某一方面的问题. 需要指出的是, 尽管 Glenister 等 (1976)提出的牙形刺“珍珠”说影响广泛，但是仍缺乏 确丵的证据证实磷质微球粒的确是牙形动物分泌的 “珍珠”，而且其具体成因机制和生理学意义仍扑朔 迷离.

本文研究的磷质微球粒中有机质的发现, 为其 生物成因的解释提供了证据. 微球粒的直径基本一 致，球形或扁球形，表面光滑且均有一个脐状浅凹; 球体内部由浅色的磷灰石和深色的有机质相间排布 而形成同心环带结构，浅凹附近的环带在一定厚度 范围重复向内凹. 这些特征反映了磷质微球粒在形 成的过程中可能受到生物组织结构的调控. 磷质微 球粒的拉曼光谱特征与牙形刺属 Palmatolepis sp.相 似，两者 XRD 模式也相同(Glenister 等，1976)，表明 二者物质结构和成分具有较大的相似性和亲缘性. 前人研究表明磷质微球粒与牙形刺具有相同部分的 地层分布时限 (Stauffer, 1935; Leuteritz 等，1972; Glenister 等, 1976; Giles 等, 2002), 绝大多数层位中 牙形刺的数量明显高于微球粒(图 2). 这些证据表明 磷质微球粒的形成可能与牙形动物有关.

研究表明，牙形动物与鱼类具有密切的亲缘关 系(Aldridge 等, 1993; Donoghue 等, 2000), 因此两者 可能会有一些相似的组织结构. 现代鱼类有三对耳 石 (矢耳石、微耳石和星耳石), 其中微耳石大小与本 文研究的磷质微球粒比较接近，也有脐状浅凹，内部 


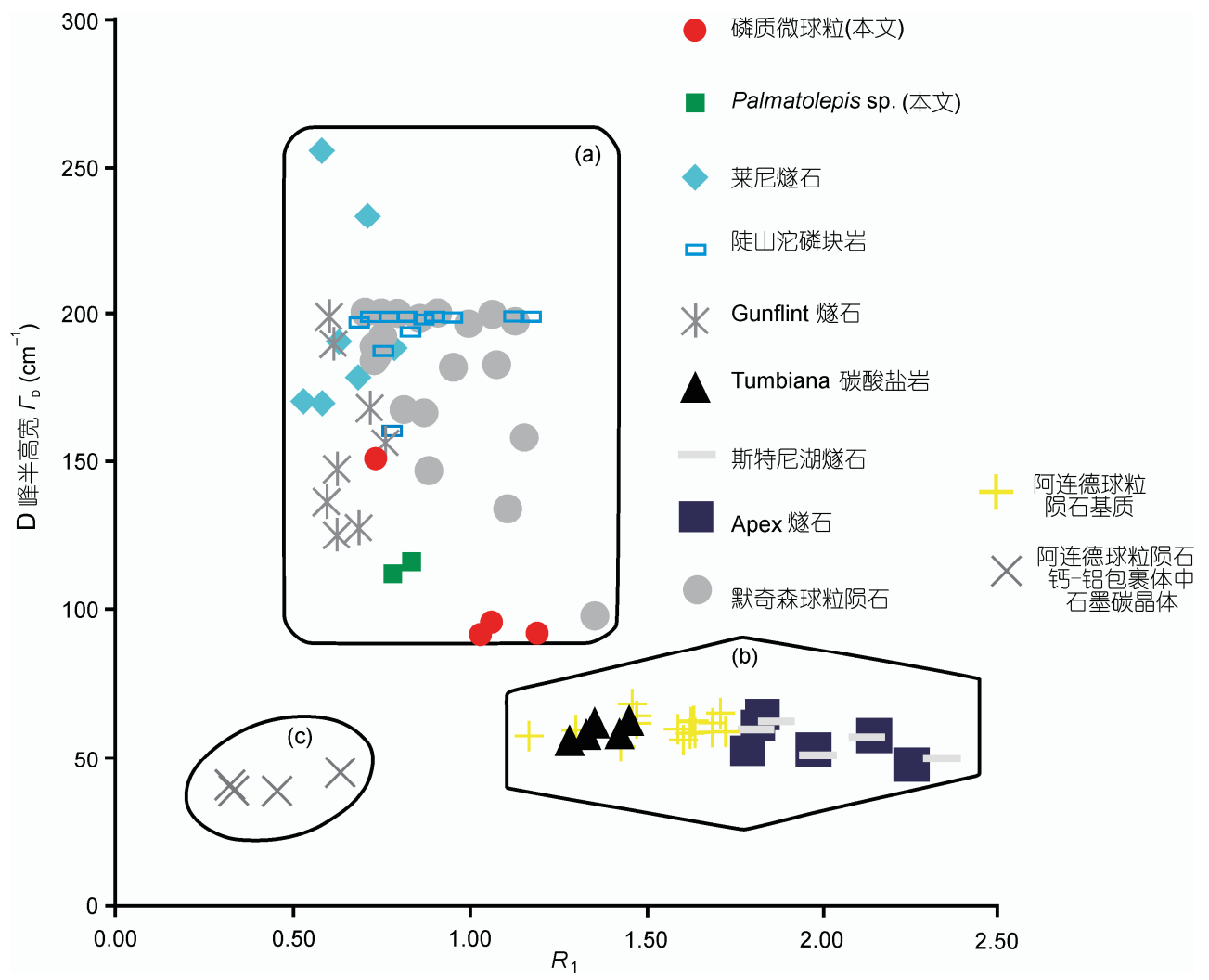

图 $6 \Gamma_{\mathrm{D}}$ 与 $R_{1}\left(I_{\mathrm{D}} / I_{\mathrm{G}}\right)$ 的关系图

(a)代表碳的原始物质为复杂有机物的样品集群; (b)代表碳的原始物质为简单有机物和热液的叠加; (c)代表阿连德钲、铝包裹体中的石墨碳晶 体. 除牙形刺和微球粒数据外, 其余数据均引自 Bower 等(2013)

主要由圆形内核和同心环状的生长轮构成, 文石和 有机质相间分布组成生长轮 (Campana 和 Neilson, 1985; Campana 和 Thorrold, 2001). 因此, 磷质微球粒 在形态和结构方面与现代鱼耳石十分相似. 尽管现 代鱼耳石由碳酸铻组成, 但是部分古生代的辐鯺亚 纲鱼(古鳕目)的耳石为磷质(Schultze, 1990). 基于以 上的证据和认识, 我们认为磷质微球粒可能是牙形 动物的 “耳石”. 现代耳石的数量明显少于牙齿的数 量, 而且耳石的生长贯穿于鱼的终生, 数量不变 (Kingsmill, 1993; Meekan 等, 1998; Campana 和 Thorrold, 2001), 这可能是磷质微球粒在数量上低于 牙形刺的原因. 需要指出的是, 在上 Pa. rhenana 带 顶部(26 层), 磷质微球粒丰度明显高于牙形刺, 这可 能与浊流和风暴浪或底流的富集和分选有关(龚一鸣 等, 2003). 虽然鱼耳石位于由耳膜隔离的内耳中, 并 浸没于内淋巴液中, 但同时也受外部环境的调控而 变化(Checkley 等, 2009). 鱼耳石的微量元素和生长
纹的宽度与周围海水温度和化学条件密切相关 (Campana和 Neilson, 1985; Giles 等, 2002). 另一方面, 耳石的成分也常常与生物演化有关(Schultze，1990). 这些原因可能是磷质微球粒与牙形刺地层分布时限 一致而层位分布却十分有限的原因. 尽管上述磷质 微球粒的特征也可以用牙形刺 “珍珠”说来解释 (Glenister 等, 1976), 但是这种假说的生理学意义却 不清楚, 所以我们从功能形态学角度认为 Youngquist 和 Miller(1948)提出的牙形动物“耳石”说可能更具说 服力.

\section{2 磷质微球粒与营养盐和菌藻类的关系}

广西杨堤剖面化学地层的研究表明, 弗拉期末 存在 $\mathrm{Fe}, \mathrm{Zn}$ 和 $\mathrm{P}$ 等营养元素的激增现象(徐再等, 2006), 营养盐激增的同时存在 $\mathrm{Al}_{2} \mathrm{O}_{3}$ 的正偏(图 7). 十分有 趣的是，我们通过对该剖面磷质微球粒丰度的统计 发现，微球粒富集于 $\mathrm{Fe}$ 和 $\mathrm{P}$ 等营养盐激增之后，滞后 
时间约 3 10 万年(图 7). 沉积学和分子地层学的研究 资料表明, F-F 之交存在菌藻类生物繁盛的迹象(龚一 鸣等, 2002a, 2002c, 2005; 徐冉等, 2006, 2008). 葛万 藻在上 Pa. rhenana 带底部和Pa. linguiformis 带顶部 十分繁盛(徐再等, 2008), 在菌藻类繁盛的同时出现 了磷质微球粒的富集(图 7). 此外, 葛万藻和磷质微 球粒富集的层位，U/Th 也增加(图 7). 这些现象说明 磷质微球粒、海洋化学条件以及菌藻类生物之间可能 存在密切联系.

海水中 $\mathrm{N}, \mathrm{P}, \mathrm{Fe}$ 和 $\mathrm{Zn}$ 等营养盐是促进生物生长 的重要元素, 通过被氧化还原在新陈代谢中起能量 载体的作用(Martin 等, 1990; Tyrrell, 1999; Boyd 等, 2000). 因此, 营养盐的富集是初级生产者繁盛的重 要物质基础, 初级生产者的繁盛又为后生动物的发 展提供了重要的食物保障. 磷质微球粒的形成表明 海洋中溶解的活性磷含量较高 (Lowenstam, 1972; Giles 等, 2002). 异常高含量的溶解活性磷被浮游植 物吸收利用使透光层的初级生产力和生物量升高, 后生动物通过捕食浮游植物或浮游动物而获得了大 量的磷(Beaugrand 等, 2003; Frederiksen 等, 2006).

溶解的磷酸盐从沉积物中释放到水体通常与河 流输入、海底火山活动以及缺氧的底层水体上涌等活 动有关(Algeo 等, 1995; Martin, 1996; Ingall 和 Jahnke, 1997; Chen 等, 2005). 自晚泥盆世以来, 裸子植物、 高大乔木、多重结构森林已经出现, 化学和生物化学 风化盛行, 使地表径流向滨-浅海输入的营养盐和有 机物的量增多(Algeo 和 Scheckler, 1998; 龚一鸣等, 2005), 最后导致这一时期海洋化学条件发生重大变 化, 从超寡营养海水转变为富营养海水(Martin, 1996; 龚一鸣等, 2005). 亲铜的重金属元素富集(白顺良, 1998; Ma 和 Bai, 2002)、Sr 同位素减少(Chen 等, 2005)、 $\mathrm{Al} / \mathrm{Al}+\mathrm{Fe}$ 比值增加(Xu 等, 2008), 海洋酸化(曾 剑威等, 2011)等现象表明, 华南晚泥盆世存在海底热 液活动, 为岩石的硅化或硅质生物及菌藻类微生物 的繁盛提供了重要物质来源(张宁和夏文臣, 1998; 王玉净和罗辉, 2004; Chen 等, 2005). 世界其他地区 如欧洲、哈萨克斯坦和乌拉尔北部同时期也存在海底 热液活动(Racki, 1998; Racki 等, 2002; Yudina 等, 2002), 并由此引发了海洋富营养化(Murphy 等, 2000; Racki 等, 2002; Chen 等, 2005). 晚泥盆世 F-F 之交的 缺氧环境(Joachimski 和 Buggisch, 1993; Joachimski 等, 2001; $\mathrm{Xu}$ 等, 2008)更有利于 $\mathrm{C}$ 的埋葬和 $\mathrm{P}$ 释放
(Ingall 和 Jahnke, 1997), 使海洋 C: P 埋葬比值(MCP) 增加(Martin, 1995, 1996; Murphy 等, 2000), 同时动荡 的海水环境促进了底部营养盐向上输送(龚一鸣等, 2003; 杜远生等, 2008), 也会造成海水营养盐升高. 因此, 陆源物质的输入、海洋缺氧、热液火山活动和 海洋营养盐富集之间具有成因上的联系性. 大量营 养盐的富集可能会诱发菌藻类微生物的繁盛. 华南、 欧洲等晚泥盆世化学地层、分子地层以及地层古生物 资料表明, 菌藻类繁盛具有跨区域的可对比性(Paris 等, 1996; Joachimski 等, 2001; Filipiak, 2002; 龚一鸣等, 2002a, 2005; 徐冉等, 2006).

通过类比现代鱼类摄食方式(Beaugrand 等, 2003; Frederiksen 等, 2006), 我们认为牙形动物可能通过间 接捕食浮游植物及浮游动物或直接吸收颗粒物, 将 海水中的活性 P 转化为生物磷, 同时受富营养化环境 的影响分泌出磷质微球粒, 最终生物磷(包括磷质微 球粒)与沉积物一起埋葬. 这个过程代表了 $\mathrm{P}$ 的输出, 并会造成生物磷的富集滞后于营养盐. 现代海洋沉 积研究表明 $\mathrm{P}$ 的驻留时间约为 3 8 万年(Ruttenberg, 1993), 与磷质微球粒相对于营养盐的滞后时间比较 吻合. 磷质微球粒的这种滞后效应可能暗示着富营 养化环境与牙形动物之间的这种调控-反馈的耦合关 系. 值得注意的是，北美、澳大利亚以及德国报道的 磷质微球粒在时间上可以与华南进行对比(Glenister 等, 1976; 龚一鸣等, 2001; Giles 等, 2002), 这可能也 是晚泥盆世全球海水富营养化一个方面的体现 (Murphy 等, 2000). 菌藻类生物为后生动物提供食物 的同时, 迅速在表层海洋环境中扩张, 而且其生长过 程中所释的 “毒素”和大量消耗海水中的溶解游离氧, 使海水进一步的缺氧和毒化, 由此加重了浅水生物 的危机 (Tappan, 1982; Filipiak, 2002; 龚一鸣等, 2002a; Chen 等, 2005).

基于磷质微球粒的详细解剖，并结合与牙形刺 在丰度的相关性、成分方面的相似性以及与鱼类耳石 在形态和结构特征方面的相似性, 我们认为磷质微 球粒可能为牙形动物 “耳石”. 需要指出的是, 本文中 磷质微球粒可能为牙形动物“耳石”的解释仅仅只是 假说而非定论. 由于缺乏足够证据, 仍无法否定牙形 刺“珍珠”说(Glenister 等, 1976), 也无法判断磷质微 球粒的形成是否与软躯体动物有关, 这都还有待于 进一步的研究. 如果牙形动物“耳石”的假说确信无 疑的话, 那么还可以对磷质微球粒开展更多有价值 


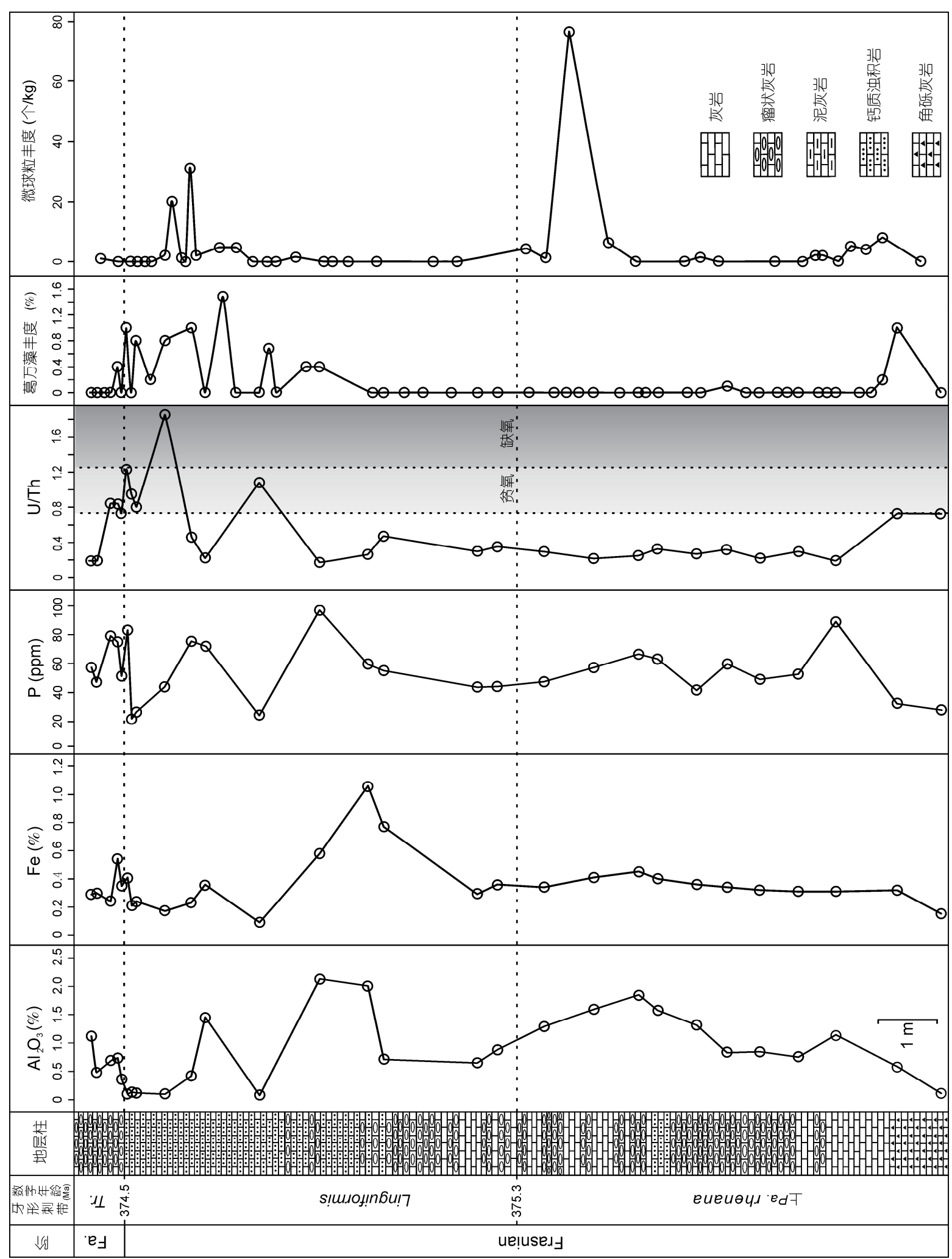

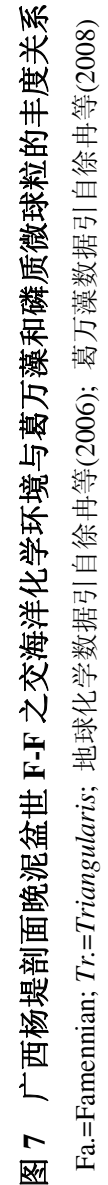


的研究, 如不同形貌结构微球粒生长轮数量的系统 统计; 判断生长轮的类型(日、月、季、年轮); 生长 轮的成分结构精细研究; 牙形动物的听觉系统特征、 寿命和生长周期的研究; 环境的高分辨率示踪等 (Campana 和 Thorrold, 2001; Campana, 2005).

杨堤剖面中磷质微球粒的分布特征可能暗示了 重要的地球生物学过程: 晚泥盆世陆源输入的增加、 海底热液活动以及缺氧的底层海水上涌等活动可能
导致了海水营养盐富集，并由此诱发菌藻类生物的 繁盛，从而可能刺激了牙形动物分泌磷质微球粒(磷 质耳石?)。尽管海水营养盐、菌藻类生物、牙形动物 以及磷质微球粒四者之间的上述联系还有待更多的 证据证实，但是本文以磷质微球粒为切入点阐述了 海洋环境、地微生物以及后生动物之间的生物-环境 耦合关系，也为 F-F之交生物大灭绝事件的海水富营 养化灭绝机制提供了新证据.

中国地质大学地球科学学院徐㕀博士在野外采样过程中给予很多帮助; 江海水博士在获取微球粒的实验过 程中, 提供了很大的帮助; 微球粒制备和测试过程中得到了地质矿产过程与资源国家重点实验室的徐海军博 士、郑建平教授、平先全和陈春飞等的帮助，谨此致谢.

\section{参考文献}

白顺良. 1998. 泥盆纪弗拉阶-法门阶事件的化学-生物地层学研究. 北京大学学报(自然科学版), 34: 363-369

杜远生, 龚一鸣, 曾雄伟, 等. 2008. 广西泥盆系弗拉斯-法门期之交的事件沉积及其对小行星碰撞引起的大海啸的启示. 中国科学 D 辑: 地球科学, 38: 1504-1513

龚一鸣, 李保华, 司远兰, 等. 2002a. 晚泥盆世赤潮与生物集群绝灭. 科学通报, 47: 554-560

龚一鸣, 李保华, 吴诒. 2002b. 广西弗拉阶-法门阶之交碳同位素与分子地层对比研究. 地学前缘, 9: 151-160

龚一鸣, 李保华, 吴诒. 2002c. 广西泥盆系弗拉阶-法门阶之交分子地层研究. 自然科学进展, 12: 292-297

供一鸣, 司远兰, 徐光辉, 等. 2001. 晚泥盆世磷质微球粒一一可能的动物卵细胞. 地质学报, 75: 441-445

龚一鸣，吴诒，杜远生，等. 1997. 华南泥盆纪海平面弯化节律及圈层耦合关系. 地质学报, 71: 212-226

龚一鸣，徐冉，李保华. 2003. 分叉波痕在广西上泥盆统钙质浊积岩中的发现及意义. 地质论评, 49: 379-382

龚一鸣, 徐由, 汤中道, 等. 2004. 广西上泥盆统轨道旋回地层与牙形石带的数字定年. 中国科学 D 辑: 地球科学, 34: 635-643

龚一鸣, 徐申, 汤中道, 等. 2005. 晚泥盆世 F-F之交菌藻微生物繁荣与集群绝灭的关系:来自碳同位素和分子化石的启示. 中国科学 D 辑:

地球科学, 35: 140-148

黄程, 徐冉, 龚一鸣. 2012. 微球粒: 跨越微观和宇观世界的重要信息载体. 地球科学一一国地质大学学报, 37: 97-116

季强. 1994. 从牙形类研究论华南弗拉斯阶-法门阶生物灭绝事件. 见: 中国地质科学院地层古生物论文集编辑委员会, 主编. 地层古生物 论文集(第 24 辑). 北京：地质出版社. 79-107

廖卫华. 2001. 中国晚泥盆世 F/F 生物集群绝灭事件及其后的生物复苏的研究. 中国科学 D 辑: 地球科学, 31: 663-667

廖卫华. 2004. 华南晚泥盆世弗拉期-法门期之交大灭绝及其后的残存与复苏. 见: 戎嘉余, 方宗杰, 主编. 生物大灭绝与复苏一一来自华 南古生代和三叠纪的证据. 合肥: 中国科学技术大学出版社. 437-456

王玉净, 罗辉. 2004. 华南晚泥盆世弗拉期-法门期之交大灭绝事件中放射虫动物群的兴衰. 见: 戎嘉余, 方宗杰, 主编. 生物大灭绝与复 苏一一来自华南古生代和三叠纪的证据. 合肥: 中国科学技术大学出版社. 381-408

吴诒, 龚一鸣, 杜远生. 1997. 华南泥盆纪层序地层及海平面变化. 武汉: 中国地质大学出版社. 110

吴诒, 周怀玲, 蒋廷操, 等. 1987. 广西泥盆纪沉积相古地理及矿产. 南宁: 广西人民出版社. 292

徐手, 龚一鸣, 曾剑威. 2008. 华南晚泥盆世弗拉期-法门期之交葛万藻与腕足动物的耦合关系. 中国科学 D 辑: 地球科学, 38: 1514-1520

徐申, 龚一鸣, 汤中道. 2006. 菌藻类繁盛：晚泥盆世大灭绝的疑凶? 地球科学一中国地质大学学报, 31: 787-797

张宁, 夏文臣. 1998. 华南晚古生代硅质岩时空分布及再扩张残留海槽演化. 地球科学一一中国地质大学学报, 23: 480-486

曾剑威, 徐再, 龚一鸣. 2011. 泥盆纪 F-F 之交海底热液活动与海洋酸化: 来自稀土元素的证据. 中国科学: 地球科学, 41: 1089-1099

曾允孚，张锦泉，刘文均，等. 1993. 中国南方泥盆纪岩相古地理与成矿作用. 北京：地质出版社. 123

Aldridge R J, Briggs D E G, Smith M P, et al. 1993. The anatomy of conodonts. Philos Trans R Soc B-Biol Sci, 340: 405-421

Algeo T J, Berner R A, Maynard J B, et al. 1995. Late Devonian oceanic anoxic events and biotic crises: "Rooted" in the evolution of vascular land plants? Geol Soc Am Today, 5: 64-66

Algeo T J, Scheckler S E. 1998. Terrestrial-marine teleconnections in the Devonian: Links between the evolution of land plants, weathering processes, and marine anoxic events. Philos Trans R Soc B-Biol Sci, 353: 113-130 
Bai S L, Bai Z Q, Ma X P, et al. 1994. Devonian Events and Biostratigraphy of South China. Beijing: Peking University Press. 303 Beaugrand G, Brander K M, Alistair Lindley J, et al. 2003. Plankton effect on cod recruitment in the North Sea. Nature, 426: 661-664 Bischoff G C O. 1973. On the nature of the conodont animal. Geol Palaeontol, 7: 147-174

Bower D, Steele A, Kater L. 2013. Micro Raman spectroscopy of carbonaceous material in microfossils and meteorites: Improving a method for life detection. Astrobiology, 13: 103-113

Boyd P W, Watson A J, Law C S, et al. 2000. A mesoscale phytoplankton bloom in the polar Southern Ocean stimulated by iron fertilization. Nature, 407: 695-702

Buggisch W. 1991. The global Frasnian-Famennian "Kellwasser Event”. Geol Rundsch, 80: 49-72

Campana S E. 2005. Otolith science entering the 21st century. Mar Fres Res, 56: 485-495

Campana S E, Neilson J D. 1985. Microstructure of fish otoliths. Can J Fish Aquat Sci, 42: 1014-1032

Campana S E, Thorrold S R. 2001. Otoliths, increments, and elements: Keys to a comprehensive understanding of fish populations? Can J Fish Aquat Sci, 58: 30-38

Checkley D M, Dickson A G, Takahashi M, et al. 2009. Elevated $\mathrm{CO}_{2}$ enhances otolith growth in young fish. Science, $324: 1683$

Chen D Z, Qing H R, Li R W. 2005. The Late Devonian Frasnian-Famennian (F/F) biotic crisis: Insights from $\delta^{13} \mathrm{C}_{\text {carb }}, \delta^{13} \mathrm{C}_{\text {org }}$ and ${ }^{87} \mathrm{Sr} /{ }^{86} \mathrm{Sr}$ isotopic systematics. Earth Planet Sci Lett, 235: 151-166

Chen D Z, Tucker M E. 2003. The Frasnian-Famennian mass extinction: Insights from high-resolution sequence stratigraphy and cyclostratigraphy in South China. Paleogeogr Paleoclimatol Paleoecol, 193: 87-111

Claeys P, Casier J G. 1994. Microtektite-like impact glass associated with the Frasnian-Famennian boundary mass extinction. Earth Planet Sci Lett, 122: 303-315

Claeys P, Casier J G, Margolis S V. 1992. Microtektites and mass extinctions: Evidence for a late Devonian Asteroid impact. Science, 257 : 1102-1104

Copper P. 1986. Frasnian/Famennian mass extinction and cold-water oceans. Geology, 14: 835-839

Donoghue P C J, Forey P L, Aldridge R J. 2000. Conodont affinity and chordate phylogeny. Biol Rev, 75: 191-251

Escribano R, Sloan J J, Siddique N, et al. 2001. Raman spectroscopy of carbon-containing particles. Vibr Spectr, 26: 179-186

Filipiak P. 2002. Palynofacies around the Frasnian/Famennian boundary in the Holy Cross Mountains, southern Poland. Paleogeogr Paleoclimatol Paleoecol, 181: 313-324

Frederiksen M, Edwards M, Richardson A J, et al. 2006. From plankton to top predators: Bottom-up control of a marine food web across four trophic levels. J Anim Ecol, 75: 1259-1268

Giles K A, McMillan N J, McCarson B L. 2002. Geochemical analysis and paleoecological implications of phosphatic microspherules (otoliths?) from Frasnian-Famennian boundary strata in the Great Basin, USA. Paleogeogr Paleoclimatol Paleoecol, 181: 111-125

Glass B P, Simonson B M. 2012. Distal impact ejecta layers: Spherules and More. Elements, 8: 43-48

Glenister B F, Klapper G, Chauff K M. 1976. Conodont Pearls? Science, 193: 571-573

Gong Y M, Li B H, Wang C Y, et al. 2001. Orbital cyclostratigraphy of the Devonian Frasnian-Famennian transition in South China. Paleogeogr Paleoclimatol Paleoecol, 168: 237-248

Ingall E, Jahnke R. 1997. Influence of water-column anoxia on the elemental fractionation of carbon and phosphorus during sediment diagenesis. Mar Geol, 139: 219-229

Joachimski M M, Breisig S, Buggisch W, et al. 2009. Devonian climate and reef evolution: Insights from oxygen isotopes in apatite. Earth Planet Sci Lett, 284: 599-609

Joachimski M M, Buggisch W. 1993. Anoxic events in the late Frasnian-Causes of the Frasnian-Famennian faunal crisis? Geology, 21: 675-678

Joachimski M M, Ostertag-Henning C, Pancost R D, et al. 2001. Water column anoxia, enhanced productivity and concomitant changes in $\delta^{13} \mathrm{C}$ and $\delta^{34} \mathrm{~S}$ across the Frasnian-Famennian boundary (Kowala-Holy Cross Mountains/Poland). Chem Geol, 175: 109-131

Johnson J G, Klapper G, Sandberg C A. 1985. Devonian eustatic fluctuations in Euramerica. Geol Soc Am Bull, 96: 567-587

Kingsmill S. 1993. Ear stones speak volumes to fish researchers. Science, 260: 1233-1234

Leuteritz K, Pietzner H, Vahl J, et al. 1972. Aufbau, zusammensetzung und entstehung von Calciumphosphat-Sphären in paläozoischen Kalken. Geol Palaeontol, 6: 111-137

Lowenstam H A. 1972. Phosphatic hard tissues of marine invertebrates: Their nature and mechanical function, and some fossil implications. Chem Geol, 9: 153-166

Ma X P, Bai S L. 2002. Biological, depositional, microspherule, and geochemical records of the Frasnian/Famennian boundary beds, South China Paleogeogr Paleoclimatol Paleoecol, 181: 325-346

Marshall C P, Edwards H G, Jehlicka J. 2010. Understanding the application of Raman spectroscopy to the detection of traces of life. Astrobiology, 10: 229-243 
Martin J H, Fitzwater S E, Gordon R M. 1990. Iron deficiency limits phytoplankton growth in Antarctic waters. Glob Biogeochem Cycle, 4: 5-12

Martin R E. 1995. Cyclic and secular variation in microfossil biomineralization: Clues to the biogeochemical evolution of Phanerozoic oceans. Glob Planet Change, 11: 1-23

Martin R E. 1996. Secular increase in nutrient levels through the Phanerozoic: Implications for productivity, biomass, and diversity of the marine biosphere. Palaios, 11: 209-219

McGhee G R. 1996. The Late Devonian Mass Extinction. New York: Columbia University Press. 303

McLaren D J. 1970. Presidential address: Time, life, and boundaries. J Paleontol, 44: 801-815

Meekan M, Dodson J, Good S, et al. 1998. Otolith and fish size relationships, measurement error, and size-selective mortality during the early life of Atlantic salmon (Salmo salar). Can J Fish Aquat Sci, 55: 1663-1673

Murphy A E, Sageman B B, Hollander D J. 2000. Eutrophication by decoupling of the marine biogeochemical cycles of C, N, and P: A mechanism for the late Devonian mass extinction. Geology, 28: 427-430

Paris F, Girard C, Feist R, et al. 1996. Chitinozoan bio-event in the Frasnian-Famennian boundary beds at La Serre (Montagne Noire, Southern France). Paleogeogr Paleoclimatol Paleoecol, 121: 131-145

Pasteris J D, Wopenka B. 2003. Necessary, but not sufficient: Raman identification of disordered carbon as a signature of ancient life. Astrobiology, 3: 727-738

Racki G. 1998. Frasnian-Famennian biotic crisis: Undervalued tectonic control? Paleogeogr Paleoclimatol Paleoecol, 141: 177-198

Racki G. 2012. The Alvarez impact theory of mass extinction; limits to its applicability and the "great expectations syndrome". Acta Palaeontol Polon, 57: 681-702

Racki G, Racka M, Matyja H, et al. 2002. The Frasnian/Famennian boundary interval in the South Polish-Moravian shelf basins: Integrated event-stratigraphical approach. Paleogeogr Paleoclimatol Paleoecol, 181: 251-297

Raup V M, Sepkoski J J J. 1982. Mass Extinctions in the fossil record. Science, 215: 1501-1503

Ruttenberg K C. 1993. Reassessment of the oceanic residence time of phosphorus. Chem Geol, 107: 405-409

Sandberg C A, Morrow J R, Ziegler W. 2002. Late Devonian sea-level changes, catastrophic events, and mass extinctions. Geol Soc Am Spec Pap, 356: 473-487

Schopf J W, Kudryavtsev A B, Agresti D G, et al. 2002. Laser-Raman imagery of Earth's earliest fossils. Nature, 416: 73-76

Schultze H-P. 1990. A new acanthodian from the Pennsylvanian of Utah, U.S.A., and the distribution of otoliths in gnathostomes. J Vert Paleontol, 10: 49-58

Simonson B M, Glass B P. 2004. Spherule layers-Records of ancient impacts. Annu Rev Earth Planet Sci, 32: 329-361

Stauffer C R. 1935. The Conodont fauna of the decorah shale (Ordovician). J Paleontol, 9: 596-620

Stauffer C R. 1940. Conodonts from the Devonian and associated clays of Minnesota. J Paleontol, 14: 417-435

Stigall A L. 2012. Speciation collapse and invasive species dynamics during the late Devonian "Mass Extinction". Geol Soc Am Today, 22: 4-9

Tappan H. 1982. Extinction or survival: Selectivity and causes of Phanerozoic crises. Geol Soc Am Spec Pap, 190: 265-276

Tyrrell T. 1999. The relative influences of nitrogen and phosphorus on oceanic primary production. Nature, 400: 525-531

Ver Straeten C A, Brett C E, Sageman B B. 2011. Mudrock sequence stratigraphy: A multi-proxy (sedimentological, paleobiological and geochemical) approach, Devonian Appalachian Basin. Paleogeogr Paleoclimatol Paleoecol, 304: 54-73

Walliser O. 1996. Global Events in the Devonian and Carboniferous. In: Walliser O eds. Global Events and Event Stratigraphy in the Phanerozoic. Berlin: Springer-Verlag. 225-250

Wang C Y, Ziegler W. 2002. The Frasnian/Famennian conodont mass extinction and recovery in South China. Senckenbergiana Lethaea, 82: 463-493

Wang K. 1992. Glassy Microspherules (Microtektites) from an Upper Devonian Limestone. Science, 256: 1547-1550

Wang K, Attrep M, Orth J C J. 1993. Global iridium anomaly, mass extinction, and redox change at the Devonian-Carboniferous boundary. Geology, 21: 1071-1074

Wang K, Chatterton B D E. 1993. Microspherules in Devonian sediments: Origins, geological significance and contamination problems. Can J Earth Sci, 30: 1660-1667

Xu B, Gu Z Y, Han J T, et al. 2008. Environmental changes during Frasnian-Famennian transition in south China: A multiproxy approach. J Geophys Res-Biogeosci, 113: 1-11

$\mathrm{Xu} \mathrm{B,} \mathrm{Gu} \mathrm{Z} \mathrm{Y,} \mathrm{Wang} \mathrm{C} \mathrm{Y,} \mathrm{et} \mathrm{al.} \mathrm{2012.} \mathrm{Carbon} \mathrm{isotopic} \mathrm{evidence} \mathrm{for} \mathrm{the} \mathrm{associations} \mathrm{of} \mathrm{decreasing} \mathrm{atmospheric} \mathrm{CO}_{2}$ level with the FrasnianFamennian mass extinction. J Geophys Res-Biogeosci, 117: 1-12

Youngquist W, Miller A K. 1948. Additional conodonts from the Sweetland Creek shale of Iowa. J Paleontol, 22: 440-450

Yudina A B, Racki G, Savage N M, et al. 2002. The Frasnian-Famennian events in a deep-shelf succession, Subpolar Urals: Biotic, depositional, and geochemical records. Acta Palaeontol Polon, 47: 355-372 